\title{
Stage III Urethral Cancer AJCC v8
}

National Cancer Institute

\section{Source}

National Cancer Institute. Stage III Urethral Cancer A/CC v8. NCI Thesaurus. Code C140462.

Stage III includes: (T1, N1, M0); (T2, N1, M0); (T3, N0, M0); (T3, N1, M0). T1: For male penile urethra and female urethra: T umor invades subepithelial connective tissue. For prostatic urethra: Tumor invades urethral subepithelial connective tissue immediately underlying the urothelium. T2: For male penile urethra and female urethra: Tumor invades any of the following: corpus spong iosum, periurethral muscle. For prostatic urethra: Tumor invades the prostatic stroma surrounding ducts either by direct extension from the urothelial surface or by invasion from prostatic ducts. T3: For male penile urethra and female urethra: Tumor invades any of the following: corpus cavernosum, anterior vagina. For prostatic urethra: Tumor invades the periprostatic fat. N0: No regional lymph node metastasis. N1: Single regional lymph node metastasis in the inguinal region or true pelvis [perivesical, obturator, internal (hypog astric) and external iliac], or presacral lymph node. M0: No distant metastasis. (AJCC 8th ed.) 